\title{
WALLACE STEVENS: O HERMETISMO COMO LEITURA DO REAL
}

\author{
Maria Luísa Fumaneri* \\ Universidade Federal do Paraná
}

Resumo: A poesia de Wallace Stevens (1879-1955) é sempre considerada um desafio à interpretação, coerente com a tradição do modernismo de Stéphane Mallarmé em Um lance de dados, graças à sua obscuridade e conteúdo filosófico. O objetivo deste trabalho é mostrar como esse paralelo entre a obra dos dois poetas pode elucidar alguns problemas que assombram a interpretação de poesia moderna, a saber: as ligações entre linguagem e realidade e o papel da poesia no conhecimento. Primeiramente, há uma análise do significado do problema, da forma como aparece na obra-prima de Mallarmé. Depois, uma tentativa de demonstrar, em alguns poemas do autor americano, como o problema é formulado em outros termos em sua teoria da poesia como Ficção Suprema. Para estes fins, os poemas escolhidos foram "Treze maneiras de olhar para um melro" e "O homem da guitarra azul", na medida em que eles demonstram duas formas diferentes de abordar a questão da relação entre representação poética e realidade.

Palavras-chave: Poesia Moderna. Hermetismo. Mallarmé. Wallace Stevens. Poesia e Realidade.

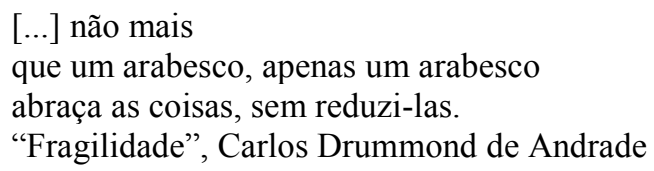

\section{Introdução}

A atração exercida por poetas como Wallace Stevens, em um primeiro momento, deve-se muito à dificuldade de suas obras, que aparecem ao leitor como enigmas cuja tentativa de decifração muitas vezes é frustrante. O problema evidente ao se analisar o hermetismo (ou a obscuridade) na poesia é sempre parecer que perdemos algo ao tentar transpô-lo para o discurso analítico. A escolha, em um poema particular ou em um projeto poético, de cifrar significados tem como objetivo primeiro resistir à análise - eis uma obviedade, porém a mais difícil de lembrar. A mente tende a buscar o significado, temos fé em um significado, nosso horizonte é a decifração. Entretanto, quando um poema escolhe

\section{Esta obra está licenciada sob uma Creative Commons - Atribuição 4.0}

\footnotetext{
* Doutoranda em Letras (Estudos Literários) pela Universidade Federal do Paraná. Professora do Instituto Superior de Educação Nossa Senhora de Sion, Curitiba, PR. E-mail: <marifumaneri@gmail.com>.
} 
deliberadamente escapar do uso cotidiano da linguagem, de sua função essencialmente comunicativa, tem-se de respeitar que "the greatest danger in explicating [...] is perhaps that of rigid over-interpretation" (SUKENICK, 1967, p. 72). A princípio, afinal, nenhum poema é obscuro à toa. Se o fosse, não despertaria interesse maior. O poema difícil, portanto, aponta tanto para o significado cifrado quanto para o significado de cifrá-lo. Assim, é necessário extrair algo de um poema difícil, considerando que sua dificuldade é parte de seu construto é um traço estilístico motivado. O outro caminho, o mais fácil e menos compensador, é simplesmente admitir que ele não diz nada e não quer dizer nada.

No caso da poesia chamada modernista, se acreditamos em analistas como Hugo Friedrich (1978) ou Theodor Adorno (1980), tal dificuldade não é simples questão de estilo individual, mas uma vantajosa saída histórica para um problema histórico: essa poesia se opõe, e se defende, de certa facilitação do discurso.

Em outro sentido, o sociológico, soma-se a interpretação de Pierre Bourdieu. Embora o hermetismo não seja a característica mais saliente de sua análise, ele aparece como consequência de um estado de autonomização do discurso poético. Entre as razões históricas para a conquista da autonomia, estariam a Revolução Industrial, o paradigma romântico, o crescimento do público leitor e o início da Indústria Cultural. A resistência da arte ao mercado, à competição, à transformação dos bens culturais em mercadoria e ao caráter amorfo (diversificado tanto em termos de estrato social quanto de capital cultural) do novo público teria erigido uma nova condição da arte. Na guerra em que se vê com o mundo moderno, o campo de produção erudita se formaria e declararia sua autonomia, sustentado pela nova ordem europeia. Tais condições históricas teriam influenciado não só o que se diz sobre a arte na era da autonomia, mas marcariam fortemente a própria produção material.

\footnotetext{
Afirmar o primado da maneira de dizer sobre a coisa dita, sacrificar o "assunto", antes sujeito diretamente à demanda, à maneira de abordá-lo, ao puro jogo das cores, dos valores e das formas, forçar a linguagem para forçar a atenção à linguagem, constituem procedimentos destinados a afirmar a especificidade e o caráter insubstituível do ato de produção artística (BOURDIEU, 2009, p. 110-111).
}

Dessa forma, a autonomização dos recursos estilísticos é sustentada por um mundo em que a arte se dirigirá a uma nova classe: aquela propriamente artística, participante de um grupo seleto em que "existir é diferir" (BOURDIEU, 1996, p. 271) - o hermetismo, portanto, é mais uma manifestação daquele “"prazer aristocrático de desagradar"” identificado por Friedrich em Baudelaire como resistência a um mundo demasiadamente unívoco e banal. O choque ocasionado pelo hermetismo não difere tanto da "estética do feio", pois é uma estética da incomunicabilidade como ideologia, como marcação de um lugar no mundo. 
Antes, porém, de considerarmos a produção artística autônoma (e, como consequência, o hermetismo) como simples reação que levaria a um encastelamento, em última análise, cínico - problema, aliás, que atormenta Bourdieu ao escrever sobre Mallarmé (1996, p. 308-311) - é necessário perguntar: seria uma ilusão de um grupo suficiente para sustentar mais de um século de arte modernista? É claro que o elitismo (no sentido de elite que detém um capital cultural) constitui parte de sua natureza, e a hipocrisia (cega ou não) dessa posição foi largamente denunciada não só por Bourdieu, mas por Edgar Wind em um livro interessantemente furioso (WIND, 1985). Entretanto, é inegável que a permanência do hermetismo como recurso não é seta que aponte para um lado só.

Nesse sentido, é de muito valor a curta conferência “A psicanálise e a história da arte" de Gombrich. Devido provavelmente ao contexto da enunciação (a palestra para psicanalistas), a pergunta de Gombrich é diferente: por que "achamos repulsivo aquilo que oferece uma satisfação óbvia demais, infantil demais" (GOMBRICH, 1999, p. 39-40)? Para Gombrich, a evolução histórica (que não pode ser lida simplesmente como progresso positivo) da arte levaria a uma nova forma de apreciação artística, em que o Impressionismo aparece como "divisor de águas entre dois modos de satisfação" (GOMBRICH, 1999, p. 42). Trata-se de uma reposição do conceito de arte que, ainda que possa e deva ter raízes nas condições históricas sustentadas por Bourdieu, aparece como uma conquista de ordem psicológica, em que a dificuldade tem compensações psíquicas (GOMBRICH, 1999, p. 43).

A não facilitação do discurso, a dificuldade em integrar elementos fragmentários que não se referem a uma tradição em que $x$ é igual a $y$, trazem um prazer muito moderno, construído na "interação entre expectativa e observação" (GOMBRICH, 1986, p. 51) que fundamenta a existência de toda a arte segundo Arte e ilusão (GOMBRICH, 1986). A participação, nossa capacidade "de reconhecer identidades através das variações da diferença, de 'dar o desconto' por condições que se alteraram [...]”' (GOMBRICH, 1986, p. 45), é não só a essência da arte, como a base sobre a qual trabalha o hermetismo. Afinal, "cada vez que nos vemos diante de um tipo de transposição alheio à nossa experiência, há um breve momento de choque e um período de ajustamento - mas é um ajustamento para o qual existe um mecanismo em nós" (GOMBRICH, 1986, p. 45).

É nesta linha que se pretende ler o hermetismo da "poesia da poesia", em uma análise comparativa entre Stéphane Mallarmé e Wallace Stevens: considerando a diversidade dos dois contextos, mas tendo sempre em mente que a principal influência do primeiro sobre o segundo é o significado fugaz que brilha ao longo do prazer do jogo. 


\section{Mallarmé: as "subdivisões prismáticas da Ideia" e o "terceiro aspecto de fusão"}

Os desafios colocados pela obra de Mallarmé são exemplares de como o hermetismo é seta que aponta para si e para fora. É sintomático disso que sua poesia seja constantemente usada como metáfora não só para a situação da poesia posterior a ele, mas mesmo como fim a ser projetado na leitura da história da poesia anterior. Friedrich chega mesmo a afirmar que os problemas colocados em sua obra resumem "a situação primordial da poesia moderna", o que explicaria “tanta veneração" (FRIEDRICH, 1978, p. 139).

O próprio Mallarmé parece sentir o espírito da época como saturado de uma problemática primordial. Em "Crise do verso", já o segundo segmento anuncia que a época “encontra pausa ou consciência" (MALLARMÉ, 2008, p. 150). Tal pausa parece, ao longo do truncado texto, uma situação de reflexão diante de um problema que parece simples (a não sujeição do gênero à tradição do verso), mas se mostra bem mais complexo. É fácil para Mallarmé superar a discussão da questão da versificação: o verso é convenção que "remunera o defeito das línguas" (MALLARMÉ, 2008, p. 155), mesmo desaparecendo parece se colocar como modelo - "a reminiscência do verso estrito é o fantasma desses jogos oblíquos" (MALLARMÉ, 2008, p. 153) - e não precisa ser levado tão a sério, já que o que contaria como critério é uma unidade da arquitetura, algo que lhe estruture enquanto obra, pois "toda alma é uma melodia, que se deve reatar, e para tanto, existem a flauta e a viola de cada um" (MALLARMÉ, 2008, p. 154).

Se o problema é simples do ponto de vista da proclamação de uma liberdade diante da tradição, rapidamente se percebe que o objetivo do texto é outro. Afinal, a pergunta que amedronta é: o que seria essa estruturação que vem substituir o verso como a saída para o problema do defeito das línguas? A apresentação feita pelo poeta no texto é uma chave de leitura bastante importante para o choque diante do poema "Um lance de dados" e, embora evidentemente não esgote suas possibilidades de interpretação, aponta para o tipo de projeto que baseia a construção desse poema, considerado por tantos como fundador de uma poética moderna - não foram poucos autores, afinal, que tiveram de se posicionar frente à tradição fundada por Mallarmé.

O que será defendido, por assim dizer, em "Crise do verso", é que a estruturação das partes transpostas (a transposição, para Mallarmé, busca antes a sugestão que a declaração taxativa, visto que esta reduziria a realidade, enquanto aquela a iluminaria) leva a um projeto que elimina o eu poético. É no “desaparecimento elocutório do poeta” que a obra em si surge, e das relações entre as partes, os fragmentos aludidos, emana a estrutura não-casual (ou seja, 
que "elimina o acaso"), uma "ordenação [...] de modo algum inata". O eu poético e o verso deixam de ser a amarração da obra, sendo substituídos pela estrutura, que "voa, para além do volume, inscrevendo [...] o almagre amplificado do gênio, anônimo e perfeito como uma existência de arte" (MALLARMÉ, 2008, p. 158). A “obra pura” é, portanto, consciente da maior das consciências de época - que a poesia serve-se da "noção pura", contrária ao uso banal do discurso, a "flor" que se sabe palavra, "ideia em si mesma e suave, ausente de qualquer buquê" (MALLARMÉ, 2008, p. 160).

Essa poesia seria, portanto, extremamente racional e amarrada. Não seria necessário submeter-se às exigências do verso, mas, e aqui já podemos nos concentrar no "Prefácio" de "Um lance de dados", as "subdivisões prismáticas da Ideia" seriam exigidas antes pelo "fio condutor latente", a "verossimilhança que se impõe" (CAMPOS, 2010, p. 151), em resumo, o pensamento, pois: "não é das sonoras unidades dos metais, das cordas, das madeiras, mas da fala intelectual em seu apogeu, que deve resultar, com plenitude e evidência, no conjunto das relações existentes em tudo, a Música” (MALLARMÉ, 2008, p. 159).

Poder-se-ia, portanto, demonstrar como todas essas pequenas unidades da Ideia se unem ao todo da estrutura-pensamento, como as pequenas estrelas se juntam na constelação, porém, para os fins deste trabalho, convém manter-se na própria estrutura-pensamento, a fim de compreender, posteriormente, como essa concepção de poesia-estrutura reaparecerá, transformada, na obra de Wallace Stevens.

O problema da projeção direta de "Crise do Verso" sobre "Um lance de dados" é que ela parece redutora demais. A fórmula seria: a organização matemática do poema, o Pensamento, como o lance de dados, abole o acaso, sendo a constelação que se coloca como saída. Porém poesia não é discurso taxativo. A constelação é saída possível, embora todo o pensamento emita um lance de dados, um lance de dados não abole ("jamais abolirá") o acaso. Se é saída, é saída possível, por um momento, e sempre tensa, equilibrada sobre a fragilidade de um jogo de azar. Além disso, o tom do poema é tudo menos ameno. Como lembra Haroldo de Campos: "a procura do absoluto, fadada por definição à falência, entrevê um êxito possível na conquista relativa sancionada por um talvez: a obra-constelação, evento humano, experiência viva e vivificante - véspera de um novo lance [...]". Assim, "do ponto de vista de uma teoria da composição, a consequência duma tal hermenêutica do Un Coup de Dés não seria a abolição do acaso, mas a sua incorporação, como termo ativo, ao processo criativo" (CAMPOS, 2010, p. 190).

Essa leitura essencialmente poética pode ser projetada ainda sobre outra leitura 
comum da estrutura de "Um lance de dados": a ontológica. Friedrich afirma que a grande contribuição de Mallarmé para a história da poesia seria exatamente esta: ao contrário de Rimbaud, cuja poesia opera no caos, sua poética é construtiva e fundadora de uma ontologia (FRIEDRICH, 1978, p. 96). Segundo José Guilherme Merquior, "Um lance de dados" é formado sobre a consciência de que, “do ser, só é possível falar por analogia”. É graças, portanto, ao não substancialismo da estrutura do poema que ele atinge uma figura de comparação - "a noção do análogo, do não-idêntico que, no entanto, admite a comparação" na qual o que está em jogo é o embate entre ato humano (existência) versus totalidade do universo, "no limite entre universo e sua localização analógica" (MERQUIOR, 1997, p. 38). Assim, a constelação aparece, de acordo com Merquior, como em Walter Benjamin, como "uma arrumação das estrelas ao gosto do limitado alcance do olhar humano", como "tãosomente a transitória configuração do dado num sistema de interpretação fadado a recair" (MERQUIOR, 1997, p. 38-39).

Por outro lado, o poema de Mallarmé não é a teoria da História de Benjamin, e o ensaio de Merquior (que na realidade é sobre Rilke), intui um problema sem se demorar sobre ele. Por que afinal o poema de Mallarmé só pode falar do Ser, de uma ontologia, por analogia? Há um aspecto do poema facilmente obscurecido pelo que ele diz, porém, se aprendemos a ler, com o poeta, os brancos, uma lacuna se impõe. Ocorre que o acaso mesmo, o curso da História ou da Natureza (antes de sua nomeação como História ou Natureza), da realidade em si, anterior a nomes, é essencialmente inominável. A linguagem, ao falar, não atinge exatamente o real físico historicamente constituído - e isso porque ela é uma realidade que não se confunde com o referente. Como muito bem nos lembra Friedrich:

\footnotetext{
A poesia pode e quer tocar o absoluto só no futuro e de forma hipotética, assim como só pode tocar as ausências (o Nada), tornando o sentido enigmático. Se quisesse assumir plenamente o absoluto da ausência de tempo e da ausência do concreto, não poderia, de forma alguma, subsistir como poesia [...] (FRIEDRICH, 1978, p. 130).
}

A "graça", por assim dizer, desse poema de Mallarmé é fundada no fato de que sua ontologia trabalha sobre uma ironia. O hermetismo, construído sobre as alusões, sugestões que criam um "clima", antes de um sentido, serve a essa ironia - o poema não pode chegar ao absoluto, porque, se chegasse, deixaria de ser linguagem. Frutos da existência única, marcada no tempo, só conhecemos em existência (só somos capazes de nomear a partir de) o lance de dados, que se repete enquanto existências linguísticas se repetirem. O acaso só existe como função hipotética, visto que ele não é linguístico, porque nem é humano, já que é um absoluto para além da concepção humana (vá lá, um “indizível”). Dá no mesmo, é claro, dizer que 
chamá-lo de acaso, conceber sua existência, tocá-lo, ainda que por meio das "subdivisões prismáticas da Ideia", é o maior exemplo da capacidade da linguagem de criar o mundo. O poema de Mallarmé pode, assim, ser lido como uma obra que não fala do acaso, afinal, mas da experiência, muito humana, do desconhecido, de estar diante da imensidão do tempo e espaço que existe para além da nossa mortalidade, mas que só intuímos e só podemos simbolizar a partir de esquemas humanos. Por isso ele está no limite da poesia (entendida aqui como linguisticamente construída), ainda que ironicamente seja um construto de linguagem.

A angústia suscitada por essa condição da poesia moderna, uma poesia cuja problemática baseia-se fortemente na palavra como um não-idêntico diante da natureza, é, afinal, a angústia do relativismo linguístico ${ }^{1}$. E, ao menos para mim, parece angústia pelo forte caráter de relativismo niilista. Mallarmé não chega a responder (nem negando, nem, é bom que se diga, afirmando o relativismo linguístico como abismo "maligno"), mas é inegável que funda uma poesia que, como aponta Costa Lima, ao não basear na physis, "cria a sua verossimilhança" ou, mais precisamente, cria seus próprios "quadros de referência", seu dicionário, ao invés de apoiá-los no real. Daí sua incomunicabilidade e dificuldade, além de sua aparência de autorreferência (COSTA LIMA, 1980, p. 223).

É dessa situação aflitiva que Wallace Stevens é herdeiro e é a partir dela que ele irá propor, ao longo de um projeto poético tão ou mais espinhoso que o de Mallarmé, seu "lance de dados": a sugestão de uma poesia que pode dizer tudo, a poesia que é atividade positiva, a ideia de poesia como "ficção suprema".

\section{“Things seen are things as seen. Absolute real": a poesia como ficção suprema}

A obra de Wallace Stevens já foi lida como neorromântica. De fato, Harold Bloom chega a projetar sobre o poema "Notes toward a supreme fiction" a resolução daquela que seria a maior das tensões românticas: tentar apreender a natureza a partir da imaginação (BLOOM, 1963, p. 78).

É fácil perceber, no entanto, que Stevens é um poeta que lida com as mesmas questões que vêm de uma tradição, embora em um tempo distinto e de forma distinta, que não pode ser resumida apenas como romântica (ainda que considerando que o termo, em Bloom, extrapola o senso comum). O que interessa aos limites deste trabalho, portanto, é levantar como o projeto da poesia como "ficção suprema", que perpassa toda a obra do poeta, colocase como uma alternativa, uma proposta, à poesia da linguagem como abismo, identificada a

\footnotetext{
${ }^{1}$ E que se perpetuou na ideia de significado da linguagem literária como engodo, de Roland Barthes (especialmente 1986 e 1988) a Stanley Fish (1993).
} 
partir do poema de Mallarmé (ao menos, em boa parte de sua recepção). Acredita-se que, antes de imputar à obra de Stevens uma "resolução" de Mallarmé, o mais interessante ao colocá-los em paralelo é ver como ambos lidam de forma diferente com a mesma questão, que é "a situação primordial da poesia moderna" identificada por Friedrich (1978, p. 179). O que se pretende é, portanto, antes, fazer uma leitura "friedrichiana" de Stevens que o ler como um profeta da poesia. Como se verá em breve, a própria noção de ficção suprema impede que se projete sobre um só poeta, ou sobre um só ser humano, a verdade sobre qualquer coisa.

Inscrito dentro da tradição de uma poesia que é essencialmente linguagem e, por isso, remete-se àquela tradição autorreferente identificada por Costa Lima, Wallace Stevens tem, seja como figura que emana de seus poemas, seja como ensaísta, plena consciência de que sua discussão se coloca na problemática diferenciação entre imaginação e realidade. Imaginação, aqui, deve ser compreendida como o trabalho da mente, fundado sobre a linguagem, que interpreta o mundo sem dominá-lo completamente. Assim, as artes em geral pertenceriam ao campo da imaginação. $\mathrm{O}$ mundo, por consequência, é a realidade, compreendida às vezes como natureza, às vezes como a vida em si (que inclui as relações humanas, tudo o que existe para além da mente, enfim ${ }^{2}$ ). Assim, "we live in the mind. [...] If we live in the mind, we live with the imagination" (STEVENS, 1951, p. 140). A primeira barreira a ser quebrada para Stevens, portanto, é opor "imaginativo" a "racional”. A razão opera a partir da imaginação (pressupondo-se que não se sai da mente ao estar no mundo), embora ela seja uma imaginação de natureza diferente, com objetivos distintos ${ }^{3}$. Se o limite entre razão e imaginação é obscuro, talvez seja porque "[...] reason is simply the methodizer of imagination" (STEVENS, 1951, p. 153).

A imaginação, irmã da razão, aparece, consequentemente, nos ensaios, como a condição inescapável do homem diante do mundo. Mas não se trata de uma condição de simples passividade, visto que a imaginação é atividade produtiva, que efetivamente influi sobre a realidade. Talvez uma das primeiras grandes tematizações da questão em sua poesia seja o estranho "Anecdote of the jar" (STEVENS, 1987, p. 36).

A primeira estranheza causada pela leitura do poema é exatamente ser ele identificado como uma "anedota". Se, de fato, trata-se de um "causo", certamente escapa ao poema qualquer sentido, seja ele exemplar, seja chistoso. A palavra aparece em outros títulos

\footnotetext{
2 "[...] reality is not that external scene but the life that is lived in it. Reality is things as they are" (STEVENS, 1951, p. 25).

${ }^{3}$ Segundo Northrop Frye, a diferença entre "razão" e "imaginação", no sentido de imaginação poética, nos ensaios de Stevens é que a imaginação tende ao particular (obra, entendida, aristotelicamente, como representação de particulares), enquanto a razão tende ao universal (conceito) (FRYE, 1963, p. 163).
} 
de Harmonium (a anedota do jarro é a última de cinco), sempre com o mesmo uso algo decepcionante, como o de uma piada cujo sentido se espera, mas não se entende (STEVENS, 1973). Atendo-se, porém, ao possível significado alegórico dessas anedotas, há um sentido comum, que são maneiras diferentes de se pensar como a relação entre $x$ e $y$ modifica $x$. No caso do jarro, temos um artefato humano assentado em meio a um ambiente natural. $\mathrm{O}$ jarro em si não tem nenhuma serventia que se esperaria de um jarro, mas, colocado sobre a colina, ele se torna uma colina sobre a colina, uma forma diante da natureza amorfa, que intensifica (e "enforma") essa natureza. Assim, um jarro postado sobre a natureza bárbara a civiliza "The wilderness rose up to it,/ And sprawled around, no longer wild". O uso da primeira pessoa apenas no início do poema "I placed a jar in Tennessee", evitando a forma eventual ("there was a jar in Tennessee") reforça a ideia de que a atividade humana transforma a natureza (ao torná-la uma forma), porém não se pode desconsiderar que a transformação só pode ocorrer na interdependência entre a atividade de pôr o jarro e o crescimento desordenado (ou, ao menos, não ordenado pelo humano) da grama. A famosa proposição de William Blake, "Where man is not nature is barren" (BLAKE, 1988, p. 38), afinal, só existe se se admite que há uma natureza para ser vista pelo olhar humano. Como defende em "Imagination as value", a imaginação, para Stevens, "is the power that enables us to perceive the normal in the abnormal, the opposite of chaos in chaos" (STEVENS, 1951, p. 153).

É importante notar, porém, que a ideia da imaginação como "enformadora" da realidade não se confunde nem com uma espécie de panteísmo, ou de uma correspondência simplesmente existente entre as coisas, tampouco com o seu contrário - uma relação simplesmente arbitrária entre tudo. A tensão entre esses dois extremos é, afinal, típica do problema do símbolo modernamente entendido: é difícil ver nas "Correspondências" de Baudelaire ${ }^{4}$ ou nas "Vogais" de Rimbaud tanto um caráter simplesmente religioso quanto uma convenção despótica. A ideia de aliar as coisas pode ser criada ficcionalmente pela obra, mas ela serve a uma causa que, declaradamente, no caso de Stevens, influi sobre a vivência diante do mundo. Nesse sentido, pode-se afirmar que Stevens revisa a ideia de correspondência. $\mathrm{O}$ fato de esses esquemas não serem engessados (não estarem na natureza mesma, mas na linguagem) não os torna essencialmente mentirosos, mas uma necessidade de ver significado na realidade - "the instinctive integrations which are the reason for living" (STEVENS, 1951, p. 155) -, ainda que o sentido que dela emane possa até ter, para um poeta, uma aparência caótica. O caos como conceito, afinal, é apenas mais uma leitura humana do que cerca o

\footnotetext{
${ }^{4}$ Segundo William York Tindall, a ideia de ficção suprema é inspirada pela "plus haute fiction" que Baudelaire cunhou para falar da religião (TINDALL, 1963, p. 30).
} 
sujeito.

Segundo os ensaios de Stevens, a forma por excelência da criação-que-intensifica a realidade é a "resemblance" (semelhança). Para ele, "all things resemble each other" (STEVENS, 1951, p. 71), mas tal semelhança nunca é identidade, pois "identity is the vanishing point of resemblance", seja na natureza ou na metáfora (STEVENS, 1951, p. 72). O caso é que a identidade acachaparia as relações entre as coisas, enquanto a semelhança, ao aproximar elementos que não são exatamente a mesma coisa, opera em um duplo sentido: mostra tanto a semelhança quanto a diferença. É por isso que, para o Stevens ensaísta, a defesa da semelhança aparece como defesa da metamorfose: ao apontar para uma semelhança, uma ambiguidade é criada (STEVENS, 1951, p. 78-79).

Esse princípio, que é lógico-linguístico, tem um duplo efeito ${ }^{5}$ na poesia de Stevens. O primeiro, identificável em muitos dos mais famosos poemas de Harmonium, é o do hermetismo de sentido aparentemente místico. A aproximação do dessemelhante pela relação de paralelismo (na metáfora ou no símile) cria um mistério que se materializa em um estado de ânimo. O segundo é a ideia de metamorfose como interpretação do ser diante do mundo (natural e social), e que se aproxima mais de uma ontologia como aquela identificada por Merquior em Mallarmé: uma teoria poética que fala do ser sempre por analogia, e aparece essencialmente nos poemas longos e discursivos (especialmente em "Notes toward a supreme fiction"), embora o efeito de mistério nunca se apague realmente em nenhum poema de Stevens - o sentido, afinal, nunca é evidente, pois a identidade reduz, enquanto a ambiguidade intensifica. Comecemos por Harmonium, mais especificamente por "Thirteen ways of looking at a blackbird" (STEVENS, 1987, p. 40-45).

Em sua leitura do poema (extraordinária, por sinal) em Musing the obscure (SUKENICK, 1967, p. 70-77), Ronald Sukenick propõe que a interpretação dele não pode ser limitada pela tentativa de estabelecer um sentido fixo para a figura constante do melro. $\mathrm{O}$ melro está lá em todas as treze seções, mas o que haveria de enganador no título é que o melro não importa - ele não teria significado estável, mas uma função constante (SUKENICK, 1967, p. 72), visto que, ao ser colocado nos mais variados contextos, tem o objetivo de focalizar o contexto, não a si mesmo. Seguindo essa leitura, creio ser possível afirmar que as treze maneiras de olhá-lo são treze sugestões sobre o funcionamento do olhar humano sobre a

\footnotetext{
${ }^{5}$ Creio ser possível relacionar esses dois "modos" de criação poética em sua obra com aqueles identificados por William York Tindall: o "estranho e imagístico" seria relacionável ao tom místico, enquanto o "corrido e discursivo" seria mais aproximável da discussão teórica. Como lembra o autor, Stevens nunca abriu preferiu completamente uma dessas opções em detrimento de outra, embora possa haver uma tendência em enfatizar uma ou outra em cada livro específico. (TINDALL, 1963, p. 22).
} 
realidade. Assim, o foco do título no melro enfatiza a ideia de linguagem atividade como mediadora, em que a imagem real não é recebida passivamente, como se fosse possível (ou útil) atingir um absoluto natural bruto. Qualquer apreciação sobre o mundo é realidade mediada, também ela completamente real. Como defendido no aforismo de "Adagia" presente no subtítulo desta seção, "things seen are things as seen" (STEVENS, 1957, s/p), e esse é o único real com que podemos realmente lidar, visto que não escapamos de nossa posição única de uma mente que interpreta o mundo. É nessa chave que pretendo reler o poema, fazendo referência a algumas das excelentes sugestões de Sukenick, embora considere que, muitas vezes, a fim de sustentar o tipo de leitura que está fazendo, o autor "puxe" a interpretação para um lado ou outro - o que, aliás, é impossível não fazer, provavelmente, na leitura desse poema, devido à sua forte tendência declarada à obscuridade.

De início (seção I), é apresentado o primeiro contraponto entre melro e a realidade: "Among twenty snowy mountains, / The only moving thing / Was the eye of the blackbird" (STEVENS, 1987, p. 40). A imagem é simples: focaliza-se o olho movente do melro na paisagem estática. Este primeiro melro parece estar, de primeira, em sentido literal, porém, quando se lê o poema algumas vezes (e se percebe que é inútil tentar ler o melro somente de forma denotativa), fica claro que se trata de um simples termo de comparação. Sukenick sugere que o melro aí é um "centro de composição", um ponto a partir do qual se forma, como numa pintura paisagística, a imagem completa (SUKENICK, 1967, p. 73). Do ponto de vista da teoria stevensiana da metáfora, o melro movendo os olhos torna a paisagem estática, pois ele funciona como estabelecimento de uma diferença. Nesse caso, o caráter relativo (no sentido de conceituação compreendida como uma realidade relacional, não substancialista) aparece em um tom misterioso, porém ainda pacificado. Não é isso que acontece em outros casos, como em XI.

Ocorre que esse sentido misterioso da realidade como relação construída a partir da mente, frequentemente de tom francamente místico, assume muitas vezes, neste e em outros poemas, outro tipo de inquietação pouco serena. Há um estado de ânimo, um mood, que é frequente em alguns poemas de Stevens, e parece ser aquele que ele descreveu em seus ensaios como o início da percepção metafórica (lembrando que a semelhança é a metáfora básica) e é aqui lido como a ideia de linguagem atividade: uma proliferação caótica de semelhanças que são percebidas como angustiantes. O exemplo evidente deste estado de ânimo é "Domination of Black" (STEVENS, 1987, p. 18-21), em que o eu lírico, ao relacionar instintivamente a cor dos açafrões, o grito dos pavões e o giro dos planetas (a 
relação, obviamente, é menos lógica que emocional) sente medo. Como não sabemos do que ele tem medo, ficamos com medo também. Tudo gira e, por girar, parece assemelhar-se de forma confusa, enquanto a noite cai furiosamente e predomina o negro - que é o próprio símbolo do desconhecido, instintivamente ameaçador. A dificuldade em atingir um sentido fixo, nesse caso, serve à construção de um estado incômodo na leitura de que há algo que não dominamos propriamente na percepção do mundo $e$ na interpretação do poema. Esse estado de primeira percepção das semelhanças gritantes entre as coisas aparece, outras vezes, como especialmente doentio. É o caso da seção III de "Six significant landscapes": "I measure myself/ Against a tall tree. / I find that I am much taller, / For I reach right up to the sun, / With my eye; / And I reach to the shore of the sea / With my ear. / Nevertheless, I dislike / The way the ants crawl/ In and out of my shadow" (STEVENS, 1973, p. 74).

Ora, o que importa aqui é mostrar como um pressuposto coerente pode causar um problema lógico, expresso pelo "dislike", por um incômodo que parece menor, mas é aqui essencial. Eu sou superior a ("muito mais alto" que) uma árvore, pois uma árvore não pode, como eu, alcançar a costa e o sol. Entretanto (e aqui a adversativa é tudo, pois constrói a autoironia), se eu considero essa afirmativa como verdadeira, preciso assumir que uma formiga é superior a mim, pois ela alcança o que me é inacessível: ela pode penetrar a minha sombra.

O que pode parecer puro relativismo, entretanto, é aqui mais uma exemplificação de como, da perspectiva da ideia de poesia como ficção suprema de que parecem nascer os poemas de Stevens, uma realidade relacional é sempre mutável: "Perhaps / The truth depends on a walk around a lake", nos diz em "Notes" (STEVENS, 1987, p. 126). Como lembra Harold Bloom, a ficção suprema nos permite partilhar da compreensão do mundo, mas "partilhar" nunca poderá ser "nos apropriar", pois só há compreensão do humano como ser condenado a indagar sempre a partir de sua realidade única como "breve evento relacional" (BLOOM, 1963, p. 78).

Voltando, portanto, à seção XI de "Thirteen", estamos diante da variação doentia da percepção metafórica. Sukenick lê essa passagem como a simples interrupção do mundo natural (o bando de melros) no mundo da fantasia (o homem que observa a sombra de sua carruagem) (SUKENICK, 1967, p. 76). Porém, como se viu, a sombra aparece frequentemente em Stevens como símbolo do aspecto angustiante (porque uma associação ou logicamente equivocada - caso de "Six significant landscapes" - ou caótica de tudo com tudo que leva a uma perda da apreensão das relações metafóricas - caso de "Domination of 
Black"). O homem que cruzava Connecticut na carruagem é atingido, como numa dor física, pelo medo (“a fear pierced him"): ele se equivoca ao tomar a sombra do tílburi por melros. O que, parece, complica esse trecho é que, embora a relação de semelhança seja errônea (a sombra de um tílburi não é a mesma coisa que um bando de melros - "he mistook"), qualquer leitor que perca alguns minutos imaginando a sombra de um tílburi de vidro (no mais, creio que tílburis de vidro sequer existam) não terá dificuldade em aceitar que ela pareceria ou, melhor, poderia ser associada a melros. Sukenick aposta na arbitrariedade do material (para ele, a questão é que é um material artificial), porém parece certo que há uma especificidade na sombra do vidro: a passagem da luz torna essa sombra movente como um bando de melros. $\mathrm{O}$ fato de o tal homem estar cruzando Connecticut (em um estado de passagem) intensifica a ideia da percepção como momentânea e fugaz. Assim, tomar sombras de carruagens de vidro por melros é falso, ainda que haja uma semelhança possível entre os dois elementos. A falsidade, porém, não está na relação entre uma coisa e outra, mas na identidade entre elas. E isso porque a identidade é redutora, enquanto a relação intensifica a diferença. Sombras não são melros, mas parecem melros - o que diz algo sobre sombras e melros, mas também sobre como olhamos para as duas coisas.

Nesse sentido, vale observar como é nessa linha que Northrop Frye lê um trecho especialmente misterioso deste poema (a seção IV), o que nos faz lamentar que ele não tenha feito uma leitura integral:

\begin{abstract}
When metaphor says that one thing "is" another thing, or that a man, a woman, and a blackbird are one, things are being identified with other things. In logical identity there is only identification as. If I say that the Queen of England "is" Elizabeth II, I have not identified one person with another, but one person as herself. Poetry also has this type of identification, for in poetic metaphor things are identified with each other, yet each is identified as itself, and retains that identity. When a man, a woman, and a blackbird are said to be one, each remains what it is, and the identification heightens the distinctive form of each. [...]A world of total simile, where everything is like everything else, would be a world of total monotony; a world of total metaphor, where everything is identified as itself and with everything else, would be a world where subject and object, reality and mental organization of reality, are one. [...] Yet it is through the particular and discrete that we reach the unity of imagination, which respects individuality, in contrast to the logical unity of the generalizing reason, which destroys it (FRYE, 1963, p. 170).
\end{abstract}

A obsessão de Frye pela ideia de particularidade, base da ideia de mímesis aristotélica, cabe bem para se pensar como Stevens compreende a ficção suprema - a relação abstrata entre particulares criada pelo olhar poético, e que é essencialmente linguística como um conhecimento de mundo. Sukenick lê "Thirteen" como fortemente ligado à tradição francesa, de Baudelaire e Mallarmé, no sentido de achar um ideal na linguagem independentemente de referente, e de Valéry, no sentido de entender a linguagem como 
ordenação que reflete a própria gênese poética (SUKENICK, 1967, p. 77). Claro que essas questões estão presentes no poema, porém, parece-me, apenas o tangenciam. O otimismo de Stevens quanto às possibilidades da linguagem como conhecimento são, afinal, bem mais norte-americanas que francesas, e seu amor a Mallarmé não obscurece sua linhagem whitmaniana, para quem "The eternal equilibrium of things is great, and the eternal overthrow of things is great,/ And there is another paradox" (WHITMAN, 2008, p. 208). O matiz de Stevens, nesse sentido, é o de homens como o William James de "The will to believe", para quem não há angústia nenhuma em encarar que não há conhecimento apriorístico, fora da existência relativa (JAMES, 1912).

Assim, o que aparece como erro, ou como estado estéril, em "Thirteen" é perder a possibilidade de intensificação da diferença produzida pela comparação. Para os limites da discussão a que nos propusemos aqui, portanto, cabe ainda um olhar para um terceiro aspecto - ou terceiro mood - presente no poema. Vimos que temos um estado de interpretação (de ordenação do mundo, em I e IV) a partir da semelhança descoberta e um estado de angústia (em que tudo se confunde com tudo, descrito em XI). O terceiro aspecto compete à questão da ideia de que a ordenação não domina para sempre, como notado por Bloom. Sabe-se que a ideia de mudança é extremamente importante para Stevens (uma das proposições de "Notes" é que uma ficção suprema “deve ser mutável”), pois ela preserva um aspecto que, se perdido, pode recair na mentira de um mundo completamente descritível - o que, além de perder o mistério, elemento caro ao poeta, leva à monotonia de que tudo é só repetição, de que a mudança é sempre uma cópia de algo que já aconteceu.

Tal proposição pode ser ilustrada pelo contraste entre VI, IX e XIII. Começando por IX, Sukenick observa que o limite que o melro marca é aquele da visão: ao voar para fora do alcance da vista, o melro fecha uma "área inteligível” (SUKENICK, 1967, p. 74), demarcada pelo olhar (limitado), mas, poderíamos também dizer, pela existência igualmente limitada. Por extensão, pode-se entender que, em XIII, o melro está imóvel - pois a percepção do espaçotempo está imóvel (“it was snowing / And it was going to snow”). O melro estático é a melancolia do monótono, que não apreende as metamorfoses que dão sentido às coisas particulares e únicas. É curioso perceber que, enquanto na primeira seção o movimento dos olhos do melro cria a estaticidade da paisagem, no último o melro, já compreendido francamente como mediação da leitura do mundo, assume uma função não contrastiva: criando um efeito bem diferente, ainda que seja uma variação sobre o mesmo tema. $\mathrm{O}$ objetivo, enfim, é esgotar as possibilidades. Em VI ainda no mesmo esquema, a sombra do 
melro que se move - e que não é ele, mas sua extensão - marca "uma causa indecifrável". O sentido do mistério é a sombra do melro cruzando uma janela tampada por "barbaric glass", apontando para a fronteira do entendimento. Relaciona-se, aqui, o gelo "bárbaro", com tudo para o que esse adjetivo aponta (selvagem, incivilizado, primitivo), com a aceitação de que há limites, e que estes são marcados a partir do contexto. Finalmente, em VII, bem no centro das treze maneiras de olhar ${ }^{6}$, temos o tom único da exaltação do melro "que anda em torno dos pés das mulheres". Haddam, segundo Sukenick, refere à cidade em Connecticut (SUKENICK, 1967, p. 75). O melro, numa palavra precisa de Sukenick, "o mundano" é a ficção mais alta: não os pássaros dourados e ideais (a imaginação voltada para além do mundo), mas uma ficção que desvenda as relações do banal, podendo assumir o tom místico e religioso aqui deslocado para uma espécie de "religião do real".

A esse respeito há uma defesa, no ensaio-poema "Three academic pieces", de que a grande ilusão seria a de que ultrapassamos o ideal. Para Stevens, a constante impressão de que resistimos ao ideal é sempre vencida por outro ideal, do qual a metáfora é parte (STEVENS, 1951, p. 81-82). A arte aparece, ainda, em “The relations between poetry and painting”, como um substituto para a perda, ou para a desconfiança, da crença (STEVENS, 1951, p. 170-171). A arte moderna, portanto, tem a função de revelar verdades que "are not the revelations of belief, but the precious portents of our own powers" (STEVENS, 1951, p. 175), pois, como defende em um dos aforismos de "Adagia", "it is the belief and not the god that counts" (1957). Assim, a grande poesia, chamada em seus ensaios de "poesia central" (STEVENS, 1951, p. 115-116), deve concentrar-se no problema da realidade, assumindo que um objeto é "the sum of its complications, seen / And unseen" (STEVENS, 1951, p. 87). O mistério do melro anda por nossos pés e, ao superar oposições tantas vezes ditatoriais entre ideal versus real, ou entre ficcional versus verdadeiro, assume um caráter sagrado que é terreno.

Resta, por último, um olhar para aquele segundo aspecto da poesia de Stevens, que se aproxima mais enfaticamente da discussão teórica. Em seus poemas mais longos, comuns depois de Harmonium, Stevens por vezes constrói grandes comentários a respeito da atividade poética. O ponto alto desse tipo de produção é "Notes toward a supreme fiction" (de Transport to Summer), no qual ele divide trinta segmentos (mais um, não numerado) em três partes cujos títulos são as três proposições para a teoria da ficção suprema: "deve ser abstrata”, “deve mudar" e "deve dar prazer" (STEVENS, 1987, p. 116-169). Apesar da

\footnotetext{
${ }^{6}$ Sukenick acredita que a ordem das seções é arbitrária - posição que, creio, deve ser relativizada.
} 
importância deste poema para a obra de Stevens ${ }^{7}$, pretendo concluir este trabalho fazendo uso de alguns trechos de outro poema longo: "The man with the blue guitar" (STEVENS, 1987, p. 62-99). A escolha se justifica por acreditar que esse poema já levanta, com dez anos de antecedência, a ideia que florescerá em "Notes". Além disso, creio que ele considera de perto a questão do abismo entre linguagem e mundo, que perpassa o problema da ficção (e da poesia) como embuste ou ilusão, limitada por uma verdade inatingível. Em suma, o poema tematiza a tensão moderna de uma poesia autorreferente, sem lugar no mundo. $\mathrm{O}$ espaço não permite uma análise exaustiva das trinta e três partes, portanto, recorrerei ao poema como ilustração da defesa de uma poesia que é conhecimento de mundo.

A primeira afirmação da ficção suprema já aparece no início de "The man with the blue guitar" (seção I): o homem do violão azul ${ }^{8}$ (com o duplo sentido próprio de "blue"), o artista, é inquirido de saída. O violão não toca as coisas como são, pois, na transposição, algo é perdido. Logo, porém, que o homem do violão assume os limites de seu instrumento, aqueles que colocaram sua arte em dúvida lhe pedem que toque, pois "uma melodia além de nós ainda somos nós". Não há aqui paradoxo. Uma representação tem uma estrutura reconhecível de combinações, mas tal estrutura existe antes na relação harmônica que na natureza do som. A ideia de abstração exigida pela ficção suprema tem, portanto, relação com o poder de seleção a partir de um meio limitado. Não é por o violão azul apresentar uma parte, limitada pelos meios, da realidade, que ele não a atinge, ainda que sempre a atinja de forma oblíqua, podendo recuperar apenas algumas estruturas dessa realidade. A questão é que a canção do violão ainda somos nós, pois é nossa. A generalização do violão é uma generalização no sentido peirceano de que "o que é geral tem o seu ser nos casos concretos que determina" (PEIRCE, 1972, p. 102).

O problema continua em IV: "So that's life, then: things as they are?[...] // A million people on one string? [...] // The feelings crazily, craftily call, / Like a buzzing of flies in autumn air, // And that's life, then: things as they are, / This buzzing of the blue guitar" (STEVENS, 1987, p. 64). Ora, se não é possível a generalização completa (“a million people on one string"), o que resta é preservar a diferença. Assim, criar uma abstração da variedade só é possível construindo uma variedade, como o violão precisa zumbir para representar o zumbido das moscas, embora dois zumbidos não sejam a mesma coisa - o zumbido, afinal, tem três graus: da multidão, das moscas e do instrumento. "The man with the blue guitar" é,

\footnotetext{
${ }^{7}$ A leitura de Harold Bloom é bastante eficiente em demonstrar não só a importância do poema para uma tradição, mas como ele ilustra a própria teoria metafórica de Stevens (BLOOM, 1963, p. 76-95).

${ }^{8}$ A referência a Pablo Picasso é reconhecida por Stevens, segundo Sukenick, embora o poeta afirmasse que não se remetia a uma obra específica do artista (SUKENICK, 1967, p. 82).
} 
como muitos poemas modernos, um poema que assume essa variedade em sua forma, ao unir diversos trechos com tons diferentes, que apresentam estados distintos de ânimo, exatamente com o objetivo de recriar a variedade. Sua dificuldade emula a dificuldade de tentar emular qualquer coisa, sabendo que algo sempre se perde. Por outro lado, assumir que essa perda é mais essencial que o que se ganha é só ponto de vista. O problema é que afirmar a irredutibilidade do mundo à criação artística faz com que se percam duas coisas. Nos diz o poema, em XIX, que o objetivo seria "Being the lion in the lute / Before the lion locked in the stone" (STEVENS, 1987, p. 82). Como lembra Sukenick, o segundo leão é irredutível, preso à sua condição de verdade inatingível (SUKENICK, 1967, p. 94). Isso, sem dúvida, leva a poesia a ser autorreferente, porém sua autorreferência não nasce do nada, mas de uma realidade, parte mental, parte social, de existência linguisticamente mediada.

XXII

Poetry is the subject of the poem, From this the poem issues and

To this returns. Between the two, Between issue and return, there is

An absence in reality,

Things as they are. Or so we say.

But are these separate? Is it

An absence for the poem, which acquires

Its true appearances there, sun's green,

Cloud's red, earth feeling, sky that thinks?

From these it takes. Perhaps it gives,

In the universal intercourse (STEVENS, 1987, p. 84-86).

Assim, o poema adquire, mas também alcança, algo da realidade, ainda que seja esse estado de ser o leão tocado diante do leão real. O fato de não se confundirem é, aqui, antes um rendimento que um prejuízo. O intercurso universal não é só tomar da realidade, mas dar a ela, no sentido de que todo poema é um construto no real. De fato, para o Stevens ensaísta: "There is always an analogy between nature and the imagination, and possibly poetry is merely the strange rhetoric of that parallel [...]" (STEVENS, 1951, p. 118).

A inapreensibilidade do mundo não seria, portanto, obstáculo se fosse integrada na própria estrutura do poema. A raiz, acredito, da dificuldade da poesia de Stevens é exatamente o fato de que o hermetismo, nas associações estranhas, na imagem que escapa antes de a entendermos, é o modo como ele representa a multiplicidade, as "Parts of a world", título de um de seus livros. E essa variabilidade não aparece só na dificuldade em apreender um mundo 
estável, mas no fato de que o próprio mundo se transforma. A ideia de metáfora que aproxima o dessemelhante buscando a metamorfose é também tirada da estrutura do real. Assim, a poesia, ficção suprema, “deve mudar”, pois o mundo muda. Em XXVII: “The sea is a form of ridicule. / The icebergs settings satirize // The demon that cannot be himself, / That tours to shift the shifting scene" (STEVENS, 1987, p. 90). O mar está no ar, no iceberg, na neve. O conceito de mar é uma abstração problemática, na medida em que o mundo se transforma, na medida em que a definição comum o torna mais raso, enquanto a poesia o torna complexo.

O problema da transformação das coisas é essencial em praticamente todos os poemas de Stevens. Em "Notes" ele insiste na ideia de que seria pior acreditar que as coisas se repetem, como se a abelha de hoje fosse a repetição da abelha do passado: "[...] this beginning, not resuming / this booming and booming of the new-come bee" (STEVENS, 1987, p. 136). A estabilidade dos conceitos, como já se disse, esgota o mundo, enquanto a flutuação deles recria sempre a sua temporalidade essencial. Uma poesia que estabilize totalmente o mundo aproximar-se-ia da desolada imagem da religião apresentada em "Sunday morning”, na qual o Paraíso aparece como uma cópia mal feita da realidade, na qual a fruta madura nunca cai e os rios nunca chegam ao mar. Por isso, enfim, o conhecido verso: "Death is the mother of beauty" (1987, p. 31-32).

A condição, portanto, de uma poesia moderna basear-se-ia, segundo essa ideia, no reconhecimento de uma temporalidade que é intrínseca à condição humana como à natureza. A tentativa de sair dessa condição se revela uma aporia sempre, como em XXXII:

\author{
XXXII \\ Throw away the lights, the definitions, \\ And say of what you see in the dark \\ That it is this or that it is that, \\ But do not use the rotted names. \\ How should you walk in that space and know \\ Nothing of the madness of space, \\ Nothing of its jocular procreations? \\ Throw the lights away. Nothing must stand \\ Between you and the shapes you take \\ When the crust of shape has been destroyed. \\ You as you are? You are yourself. \\ The blue guitar surprises you (STEVENS, 1987, p. 96-98).
}

A condição humana só aparece, portanto, como prisão, ao se recair no erro de acreditar que ela é uma prisão. Não há como lutar com armas que não se tem. A poesia pode 
questionar sua validade, mas apenas a partir de si, de dentro - aí repousa sua condição e sua ironia. Se ela pode, em suma, chegar ao seu limite, é só a partir de si. A revelação, dada ao artista pelo violão azul, é que só se concebe o que está fora da linguagem de dentro da linguagem, como só se concebe o que está fora da existência de dentro da existência, mas não há aí mentira, ou perda. Daí o tom relativamente otimista da seção final do poema:

\author{
XXXIII \\ That generation's dream, aviled \\ In the mud, in Monday's dirty light, \\ That's it, the only dream they knew, \\ Time in its final block, not time \\ To come, a wrangling of two dreams. \\ Here is the bread of time to come, \\ Here is its actual stone. The bread \\ Will be our bread, the stone will be \\ Our bed and we shall sleep by night. \\ We shall forget by day, except \\ The moments when we choose to play \\ The imagined pine, the imagined jay (STEVENS, 1987, p. 98).
}

O fragmento é bem autoexplicativo. A ideia de sonho, trabalhada duplamente no trecho, contém em si o resumo das três proposições de "Notes". O primeiro sonho, figurado, a quimera, abstração que se esgota no tempo, coloca em jogo a superação do homem pela morte. "O único sonho que eles conheceram" se esgota com a transformação temporal da geração que se perde, e se reconhece sempre como tempo final. O segundo sonho, literal, é aquele noturno, fabricado pela mente, e esquecido durante o dia da vida das coisas como são. Mas há algo a mais: vive-se e morre, não tem jeito, mas há momentos em que se escolhe tocar, em que o arbítrio permite olhar para a configuração das coisas a partir da imaginação. Desistir, acusar a imaginação de falseamento da realidade, é, claro, uma opção. Mas, no final do poema, essa desistência é um esquecimento. O que se esquece, enfim, é o poder da mente de criar mundos imaginados, mas ainda assim que criam algo no mundo. Assim, se, como nos diz em "Adagia", "realism is a corruption of reality", é porque "poetry increases the feeling for reality", já que "to read a poem must be an experience, like experiencing an act" (STEVENS, 1957, s./p.).

O tipo de conhecimento, associável ao prazer da poesia, parece bem parecido com aquele descrito por James M. Redfield: 
Aristotle ground imitative poetry on the most primitive sort of recognition: the child who looks at a picture book and says "cow". Aristotle says that the child thereby has some share of the philosophical pleasure of learning.

But here we have a problem. What does the child learn? [...] the child does not point and say "picture of a cow"; he says "cow". He recognizes, not the imitation, but the original. And the original - cow - he already knew; otherwise he would not have recognized it in the imitation. So in what sense can he be said to learn anything?

The key word in Aristotle's passage is sullogizesthai; Aristotle says that "we reason out" what each thing is. The learning occurs in this process of reasoning out, which itself occurs because the imitation presents us with a problem. A picture of a cow is really very little like a cow. In fact, an imitation must be unlike the original to be an imitation; an imitation cow which was just like a cow would be a cow. Imitation implies certain likenesses in a context of unlikeness. A picture of a cow shares with a cow certain common features; by these features we recognize the model. [...] That is the syllogism: we say, "everything with these features is in some sense a cow. This thing has those features. Therefore this thing is in some sense a cow." The content of our learning is not "cow" but "features-of-cow." (REDFIELD, 1994, p. 53-54).

Negar à poesia esse poder é um desserviço, além de ser redutor. Ainda que as características importantes de uma vaca mudem com o tempo - o verossímil, afinal, é cultural e historicamente variável, e certamente um poema de Stevens seria inverossímil para Aristóteles (1979) -, nada se perde. E isso porque a temporalidade da existência recupera essas configurações anteriores, reinterpretando-as infinitamente. Diz-nos Stevens: “All history is modern history" (1957). Um lance de dados não se perde no acaso se vemos a História como a via Walter Benjamin: como um "tempo saturado de 'agoras" (BENJAMIN, 1994, p. 229), pois o fato histórico "se transforma em fato histórico postumamente" (BENJAMIN, 1994, p. 232). A faculdade mimética - a capacidade de ver semelhanças -, afinal, nos diz Benjamin, pode ter se perdido na leitura dos astros, mas preserva-se na leitura profana.

[...] a linguagem seria a mais alta aplicação da faculdade mimética: um medium em que as faculdades primitivas da percepção do semelhante penetraram tão completamente, que ela se converteu no medium em que as coisas se encontram e se relacionam, não diretamente, como antes, no espírito do vidente ou do sacerdote, mas em suas essências, nas substâncias mais fugazes e delicadas [...].

Porém o ritmo, a velocidade na leitura e na escrita, inseparáveis desse processo, seriam como o esforço, ou o dom, de fazer o espírito participar daquele segmento temporal no qual as semelhanças irrompem do fluxo das coisas, transitoriamente, para desaparecerem em seguida. Assim, mesmo a leitura profana, para ser compreensível, partilha com a leitura mágica a característica de ter que submeter-se a um tempo necessário, ou antes, a um momento crítico que o leitor por nenhum preço pode esquecer se não quiser sair de mãos vazias (BENJAMIN, 1994, p. 112$113)$.

Parece ser esse o convite de leitura que nos faz a obra de Stevens. Por meio do hermetismo, ele tenta nos fazer entrever um hino a um mundo vário e mutável, ainda que como a percepção fugaz de uma imagem projetada no céu. Mas essa imagem, parece nos dizer, é o único céu que temos. 


\section{Referências}

ADORNO, Theodor W. Conferência sobre lírica e sociedade. In: BENJAMIN, Walter et al. Os Pensadores. São Paulo: Abril Cultural, 1980, p. 193-208.

ARISTÓTELES. Poética. In: Os Pensadores. São Paulo: Abril Cultural, 1979.

BARTHES, Roland. Novos ensaios críticos. O grau zero da escritura. São Paulo: Cultrix, 1986.

. O rumor da língua. São Paulo: Brasiliense, 1988.

BENJAMIN, Walter. A doutrina das semelhanças. Sobre o conceito de História. In:

Magia e técnica, arte e política: ensaios sobre literatura e história da cultura. São Paulo: Brasiliense, 1994.

BLAKE, William. The complete poetry \& prose of William Blake. New York: Anchor Books, 1988.

BLOOM, Harold. Notes toward a supreme fiction: a commentary. In: BORROFF, Marie (Org.). Wallace Stevens: a collection of critical essays. Englewood Cliffs: Prentice-Hall, 1963, p. 76-95.

BOURDIEU, Pierre. A economia das trocas simbólicas. São Paulo: Perspectiva, 2009.

Letras, 1996.

. As regras da arte: gênese e estrutura do campo literário. São Paulo: Companhia das

CAMPOS, Augusto et al. Mallarmé. São Paulo: Perspectiva, 2010.

COSTA LIMA, Luiz. Mímesis e modernidade: formas das sombras. Rio de Janeiro: Edições Graal, 1980.

FISH, Stanley. Como reconhecer um poema ao vê-lo. Palavra. Rio de Janeiro: PUC, n. 1, p. 156-165, 1993.

FRIEDRICH, Hugo. Estrutura da lírica moderna. São Paulo: Duas Cidades, 1978.

FRYE, Northrop. The realistic oriole: a study of Wallace Stevens. In: BORROFF, Marie (Org.). Wallace Stevens: a collection of critical essays. Englewood Cliffs: Prentice-Hall, 1963, p. 161-176.

GOMBRICH, Ernst H. A psicanálise e a história da arte. In: GOMBRICH, E. H. Meditações sobre um cavalinho de pau e outros ensaios sobre teoria da arte. São Paulo: Editora da Universidade de São Paulo, 1999. p. 30-44.

. Arte e ilusão. São Paulo: Martins Fontes, 1986.

JAMES, William. The will to believe: and other essays in popular philosophy. Longmans, Green, and co., 1912. E-book. Disponível em: <http://www.gutenberg.org/files/26659/26659h/26659-h.htm>. Acesso em: 09 maio 2013. 
MALLARMÉ, Stéphane. Crise de verso. Inimigo rumor: revista de poesia, São Paulo, n. 20, p. 150-164, 2008.

MERQUIOR, José Guilherme. A astúcia da mímese: ensaios sobre lírica. Rio de Janeiro: Topbooks, 1997.

PEIRCE, Charles Sanders. Semiótica e filosofia. São Paulo: Cultrix, 1972.

REDFIELD, James M. Imitation. In: REDFIELD, J. M. Nature and culture in the Iliad: the tragedy of Hector. Durham: Duke University Press, 1994.

STEVENS, Wallace. Adagia. In: Opus Posthumous: poems, plays, prose, 1957. Disponível em: $\quad<$ http://books.google.com.br/books?id=qztUqewMpa0C\&printsec=frontcover\&hl=pt$\mathrm{BR} \&$ source $=\mathrm{gbs} \_g e \_s u m m a r y \_r \& c a d=0 \# \mathrm{v}=$ onepage \&q\&f=false> . Acesso em: $13 \mathrm{fev} .2014$.

. Poemas. São Paulo: Companhia das Letras, 1987.

. The collected poems of Wallace Stevens. New York: A. Knopf, 1973.

Books, 1951.

. The necessary angel: essays on reality and the imagination. New York: Vintage

SUKENICK, Ronald. Wallace Stevens, Musing the obscure: readings, an interpretation, and a guide to the collected poetry. New York: New York University Press, 1967. Disponível em:< http://davidlavery.net/feigning/wsrg/Musing/index.htm>. Acesso em 13 fev. 2014.

TINDALL, William York. Wallace Stevens. São Paulo: Martins, 1963.

WHITMAN, Walt. Folhas de relva. São Paulo: Iluminuras, 2008.

WIND, Edgar. Art and Anarchy. USA 3rd edition: Northwestern University Press, 1985.

[Recebido em fevereiro de 2016 e aceito para publicação em abril de 2016]

\section{Wallace Stevens in the Hermetic tradition}

Abstract: Wallace Stevens (1879-1955) poetry was always reputable as a challenge to interpretation, coherent with the tradition of the modernism of Stéphane Mallarmé's $A$ throw of dice thanks to its obscurity and philosophical content. The aim of this work is to show how this parallel can elucidate some problems that round the interpretation of modern poetry, namely: the links between language and reality and the poetry part in knowledge. First of all there is an analysis of the meaning of the problem as it appears in Stéphane Mallarmé's masterpiece. Afterwards, an attempt to demonstrate in some poems of the American author how the problem is formulated in other terms in his theory of poetry as Supreme Fiction. For these purposes the poems chosen were "Thirteen ways of looking at a blackbird" and "The man with the blue guitar", insofar they demonstrate two different forms of approaching the question.

Keywords: Modern Poetry. Hermetic Tradition. Mallarmé. Wallace Stevens. Poetry and Reality.

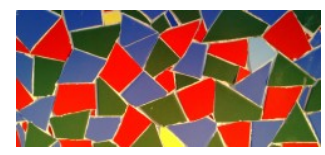

